\title{
Assessment of Associated Factors of Tuberculosis among HIV/AIDS Patients in Misha District, Hadiya Zone, Southern Ethiopia
}

\author{
Tilahun Ermeko ${ }^{1}$, Firehiwot Lire ${ }^{2}$, Abate Lette $^{1}$, Yonas Lamore ${ }^{3,}$, and Debebe Wordofa ${ }^{1}$ \\ ${ }^{1}$ Department of Public Health, Goba Referral Hospital, Madda Walabu University, Bale Goba, Ethiopia \\ ${ }^{2}$ Anjama Health Center, Misha District, SNNPR, Ethiopia \\ ${ }^{3}$ Department of Environmental Health Science, Debre Markos University, Debre Markos, Ethiopia
}

*Corresponding author: Yonas Lamore, Department of Environmental Health Science, Debre Markos University, Debre Markos, Ethiopia, E-mail: yonas384@ gmail.com

Received: 26 Mar, 2021 | Accepted: 26 Apr, 2021 | Published: 04 May, 2021

Citation: Ermeko T, Lire F, Lette A, Lamore Y, Wordofa D (2021) Assessment of Associated Factors of Tuberculosis among HIV/AIDS Patients in Misha District, Hadiya Zone, Southern Ethiopia. J HIV AIDS 7(1): dx.doi.org/10.16966/2380-5536.180

Copyright: ( 2021 Ermeko T, et al. This is an open-access article distributed under the terms of the Creative Commons Attribution License, which permits unrestricted use, distribution, and reproduction in any medium, provided the original author and source are credited.

\begin{abstract}
Introduction: Tuberculosis (TB) is a non-degenerative disease, which has a high negative health impact on both developed as well as developing countries. HIV, AIDS has increased the chance of TB occurrence.

Objective: This study was aimed to assess the association of TB among HIV/AIDS patients in misha district, hadiya zone, southern Ethiopia.

Methods: The data were collected by using a retrospective review analysis of patients' medical records. A total of 172 HIV/AIDS sampled medical records were reviewed from the registration book and variables were recorded. The data was edited and entered into Epi-info version 7 and analysed using SPSS version 21 software. Descriptive and analytical statistics bivariate and multivariate analyses were used to determine dependent and independent variables.

Results: A total of 172 ART clients' medical records were reviewed. Significant numbers of HIV clients were with Tuberculosis. Twenty-nine (16.9\%) of ART clients were with tuberculosis. Only (38.8\%) of the participants had a CD4 level of more than 350 cell/mm $\mathrm{mm}^{3}$ The majority ( $\left.84.3 \%\right)$ of patients had not received INH prophylaxis.

Conclusion and recommendation: Significant numbers of HIV clients were with Tuberculosis. The mature WHO clinical stages were highly associated with Tuberculosis. Patients having low CD4 numbers (CD4 $<200$ cell/ $/ \mathrm{mm}^{3}$ ) were more likely affected by TB. In addition, patients who had not taken INH were at risk of the occurrence of TB. Therefore, it is very important to keep the CD4 level as high as possible, and INH prophylactic preventive measures should be strengthened to manage cases as early as possible to reduce the burden incidence.
\end{abstract}

Keywords: Tuberculosis; Opportunistic infection; Mature WHO clinical stages; TB/HIV co-infection

Abbreviations and Acronyms: AFB: Acid Fast Bacilli; AIDS: Acquired Immune Deficiency Syndrome; ART: Anti-Retroviral Treatment; CD4: Subgroup of T-lymphocytes carrying CD4 antigens; CPT: Co- Trimoxazole Preventive Treatment; FMOH: Federal Ministry of Health; HIV: Human Immunodeficiency Virus; INH: Isoniazid; NEMMH: Nigist Elleni Mohammed Memmorial Hospital; Ols: Opportunistic Infection; PLWHA: People Living With HIV/AIDS; SNNPR: Southern Nations Nationalities People Region; SPSS: Statistical Package for Social Sciences; TB: Tuberculosis; TB +ve: TB Positive; WCU: Wachemo University; WHO: World Health Organization

\section{Background}

Tuberculosis (TB) is highly common opportunistic infection and the leading cause of death in HIV patients in developing countries, and shares the burden about $40 \%$ of all manifestations seen in HIV patients. Tuberculosis (TB) and Human Immune Deficiency Virus (HIV) have been associated the emergence of Acquired Immune Deficiency Syndrome (AIDS) [1]. Human Immuno Deficiency Virus (HIV) increases susceptibility to infection with the risk of progression to TB disease. The lifetime risk of HIV positive individuals to develop $\mathrm{TB}$ is 26 to 31 times greater than HIV negative individuals [2].
Developing countries like sub Saharan Africa where high prevalence of (HIV/AIDS) burden found, the TB Case Notification Rate (CNR) has increased four to six folds [3,4]. Clients with HIV are increasingly infected with tuberculosis because, HIV/AIDS affects their immunity against diseases [5-11]; because HIV/AIDS fuels the tuberculosis epidemics in many ways, such as promoting progression to active tuberculosis, increasing the risk of reactivation of latent tuberculosis infection, as well as increasing chance of tuberculosis infection once exposed to tubercle bacilli $[1,12]$. The Global report of 2013 showed that $(13 \%)$ of the infection were reported for TB patients in the African region, among these $41 \%$ of those with an HIV test result 
were positive when compared with $46 \%$ in 2011 and $43 \%$ in 2012. The ranges of positivist of HIV clients for tuberculosis ranges from $28 \%$ to $74 \%$. The study conducted in Angola, Ethiopia, Malito, Lesotho and Swaziland revealed this truth [3,12]. Globally averages across all regions were $18 \%$ and $20 \%$ among the 41 prone TB/HIV burden countries in 2013 [5].

According to different studies, TB/HIV co-infection has been associated with different age groups, sex, residence and clinical presentation of TB. The most frequently reported age group was $\geq 18$ years $[1,6,13,14]$. In contrary to this studies conducted in Ethiopia and Nigeria showed significant association between female sex and HIV co-infection in TB patients [1]. Concerning residence area and TB type the high prevalence of HIV was observed in patients of urban residents $[11,12,14,15]$, and at pulmonary positive test results $[6,8]$. HIV/AIDS has faced a number of impacts on TB patients and its control program. HIV has complicated the TB control program, by requiring more resources for diagnosis and treatments. As the number of TB cases increasing, the treatment outcomes have been decreased $[6,8]$. Studies showed that as the proportion of smear positive cases increased; the rate of treatment failure, defaulter and death, which in turn increases compromising of the progress towards achieving the targets recommended for TB control under DOTS strategy [3,7].

Therefore, in addition to one of the nationally recommended TB/HIV collaborative activity surveillance, conducting operational research to assess the prevalence of TB co-infection among HIV/ AIDS patients helps to understand the extent and trend of the coepidemic [12]. Furthermore, measuring the proportion of TB-positive HIV/AIDS patients gives important information on targeting of resources, strategic planning of activities, and monitoring the effectiveness of TB prevention care and treatment interventions overtime [4]. It could be used as an estimate of the rate of TB infection in the general population [1].

Correct diagnosis and treatment of tuberculosis help to reduce the burden of tuberculosis, provided that infectious cases are detected and treated successfully [4]. Even if this is the case, there are obstacles in implementing the goal of reducing the tuberculosis burden due to a number of challenges, such as difficulties in diagnosing tuberculosis in $\mathrm{HIV}$ infected patients due to unusual clinical picture with increase in smear negative acid fast bacilli (AFB negative) pulmonary tuberculosis disease, and atypical findings on chest radiography $[9,10]$. Therefore, this study aims to determine the prevalence of TB among HIV/AIDS patients in NEMMH. HIV infection is the single most important fueling agent for ever-increasing prevalence of tuberculosis in Ethiopia $[9,10]$. Furthermore, TB is a well-recognized opportunistic infection in patients with HIV/AIDS.

Despite the purposes, there is no such investigation done in the setting. Besides this, inconsistencies were seen in studies results concerning factors associated with HIV co-infection in TB patients.

\section{Materials and Methods}

\section{Study design, settings and study period}

An institution based cross sectional study was carried out from February 20/2018 to February 30/2018 in Nigist Eleni Mohammed memorial referral hospital, Wachemo University. The hospital is found in Hossana town which is $232 \mathrm{~km}$ far from Addis Ababa, and $157 \mathrm{~km}$ from capital city of SNNPR, Hawassa town.

The hospital provides different preventive, curative and rehabilitative services for the community. The hospital provides different services, such as chronic cares, such as HIV/AIDS care and follows up. During the study period 3,422 patients were registered, but 1925 were not on ART service, the remaining was on ART in Nigist Eleni Mohammed memorial referral hospital.

\section{Sample size determination}

The required sample was calculated by using single population proportion formula as follow proportion.

$$
n=\frac{z\left(\frac{\alpha}{2}\right)^{2} P(1-P)}{d^{2}}
$$

The following parameters were used during sample size determination.

Where, $\mathrm{n}=$ Sample size

$\mathrm{Z}=\mathrm{is}$ the Confidence interval taken as 1.96 confidence

$\mathrm{P}=$ Population proportion for prevalence of TB among HIV/AIDS patient $(18.2 \%)$ which is taken from a study conducted in Hawassa University referral hospital.

$\mathrm{d}=$ tolerated margin of error to be and is taken as $5 \%(0.05)$.

So that; $n=\frac{\left(z \frac{\alpha}{2}\right)^{2} P(1-P)}{d^{2}}=\frac{(1.96)^{2} 0.182(1-0.182)}{0.05 \times 0.05}$

$n=229$

Since the study population was below 10,000 , so we used population correction formula.

$$
N f=\frac{n}{1+\frac{n}{N}}=\frac{229}{1+\frac{229}{483}}=156+10 \%(\text { non }- \text { response rate })=172
$$

\section{Sampling technique}

A simple random sampling was used to select sampled medical cards after preparing a sampling frame containing list of card numbers of HIV/AIDS patients who were registered under ART follow up from 01/02/2015 to 30/01/2018 at Wachemo University, Nigist Eleni Mohammed memorial referral hospital.

\section{Data processing and analysis}

After collection, each data were checked for completeness data was analyzed both analytical and descriptive statistics by using SPSS version 24. Both predictors and outcome variables were filtered.

\section{Data quality assurance}

Two days training was given for data collectors and supervisors. Regular supervision was continuously done by principal investigators. Patient cards were pre checked by using data collection format. The collected data were cross checked manually before, during and after data collection for any missing, repetition and incorrect recordings.

\section{Ethical Consideration}

Ethical clearance was obtained from ethical review committee of Wachemo University and letter of permission was submitted to WCUNEMMRH medical director office to get permission and cooperation in order to conduct the study and to get access in to patient 
records. Confidentiality of collected data was assured throughout the study process.

\section{Result}

A total of $172 \mathrm{HIV} / \mathrm{ADIS}$ positive clients' medical records having required information were reviewed. Out of 172 people living with AIDS (PLWA), the majorities (64.5\%) were females; half of them (49.4\%) were in the age range 30-44 years. Regarding occupation, around forty four percent of them were governmental workers. One thirds $(33.7 \%)$ of the participants lived in rural area. Three fourths (76.7\%) of the respondents were married. The majority (58.9\%) of participants were weighted from 50 to $74 \mathrm{~kg}$. Regarding smoking status and alcohol consumption, seventy seven percent of the participants were nonsmokers and only one thirds (31.4\%) of the patients were drinking alcohol (Table 1).

\section{Clinical and laboratory profiles}

Twenty nine (16.9\%) of the study participants were found to have tuberculosis. One thirds (37.7\%) of them were on WHO stage one. Regarding functional status, the majority (93.6\%) of respondents

Table 1: Socio-demographic characteristics of study participants in Nigist Eleni referral hospital, Wachemo University, southern Ethiopia, 2018.

\begin{tabular}{|c|c|c|}
\hline Variables & Frequency & Percent \\
\hline \multicolumn{3}{|c|}{ Age categories } \\
\hline$<15$ & 9 & 5.2 \\
\hline $15-29$ & 50 & 9.1 \\
\hline $30-44$ & 85 & 49.4 \\
\hline $45-60$ & 24 & 14 \\
\hline$>60$ & 4 & 2.3 \\
\hline \multicolumn{3}{|c|}{ Sex } \\
\hline Female & 111 & 64.5 \\
\hline Male & 61 & 35.5 \\
\hline \multicolumn{3}{|c|}{ Occupation } \\
\hline Student & 29 & 16.9 \\
\hline Governmental & 76 & 44.2 \\
\hline Private & 57 & 33.1 \\
\hline Others & 10 & 5.8 \\
\hline \multicolumn{3}{|l|}{ Residence } \\
\hline Urban & 114 & 66.3 \\
\hline Rural & 58 & 33.7 \\
\hline \multicolumn{3}{|c|}{ Marital status } \\
\hline Unmarried & 37 & 21.5 \\
\hline Married & 132 & 76.7 \\
\hline Divorce & 3 & 1.7 \\
\hline \multicolumn{3}{|c|}{ Weight in kg } \\
\hline$<25$ & 5 & 3 \\
\hline $25-49$ & 54 & 32.1 \\
\hline $50-74$ & 99 & 58.9 \\
\hline$>74$ & 10 & 6 \\
\hline \multicolumn{3}{|c|}{ Smoking status } \\
\hline Non smoker & 133 & 77.3 \\
\hline Smokers & 39 & 22.7 \\
\hline \multicolumn{3}{|c|}{ Alcohol intake } \\
\hline Yes & 54 & 31.4 \\
\hline No & 118 & 68.6 \\
\hline
\end{tabular}

were working. Around forty percent of the participants had CD4 level more than $350 \mathrm{cell} / \mathrm{mm}^{3}$. The majority $(84.3 \%)$ of patients had not received INH prophylaxis. Ninety percent of the patients had used CTX prophylaxis. Concerning ART status, the majority (98.3\%) of participants were ART client; and only $1.7 \%$ of the patients were died (Table 2).

\section{Factors associated with occurrence of TB}

This study revealed that the prevalence of TB-HIV co-infection was reported 16.9\% (95\% CI: (11.0, 22.5). Clinical stage III (AOR=2.5), clinical stage IV (AOR=3.1), CD4 level of greater than $350 \mathrm{cell} / \mathrm{mm}^{3}$ $(\mathrm{AOR}=0.61)$, and not received $\mathrm{INH}$ prophylaxis $(\mathrm{AOR}=3.6)$ were significantly associated with prevalence of tuberculosis (Table 3 ).

\section{Discussion}

In this study, the prevalence of TB-HIV co-infection was reported 16.9\%. The finding was consistent with studies conducted in Hawassa (18.2), India (17\%), Nigeria $(16.8 \%, 14.4 \%, 9.6 \%)$ [1-4]. However, relatively higher prevalence has been reported from $\mathrm{Nepal}(27.3 \%)$ and Nigeria $(22.7 \%)$ [5,6], and lower results were reported from Northern Tanzania (8.3\%) [7]. This in significant variation on the magnitude of tuberculosis in HIV/AIDS patients may be due to differences regarding HIV infection rate in the population, availability of TB diagnostic facilities, and health care awareness of the community to seek health care for both TB and HIV.

The most significant factor for development of TB in HIV/AIDS patients as it is repeatedly reported in studies is the immunological condition of the person. Keeping the CD4 positive cell level as high as

Table 2: Clinical and laboratory profiles of study participants in Nigist Eleni referral hospital, Wachemo University, southern Ethiopia, 2018.

\begin{tabular}{|c|c|c|}
\hline Clinical data & Frequency & Percent \\
\hline \multicolumn{3}{|c|}{ TB diagnosed } \\
\hline Positive & 29 & 16.9 \\
\hline Negative & 143 & 83.1 \\
\hline \multicolumn{3}{|c|}{ WHO stage } \\
\hline Stage 1 & 63 & 37.5 \\
\hline Stage 2 & 42 & 25 \\
\hline Stage 3 & 42 & 25 \\
\hline Stage 4 & 21 & 12.5 \\
\hline \multicolumn{3}{|c|}{ Functional status } \\
\hline Working & 161 & 93.6 \\
\hline Ambulatory & 9 & 5.2 \\
\hline Bedridden & 2 & 1.2 \\
\hline \multicolumn{3}{|c|}{ CD4 count } \\
\hline$<200$ & 38 & 28.4 \\
\hline $200-350$ & 44 & 32.8 \\
\hline$>350$ & 52 & 38.8 \\
\hline \multicolumn{3}{|c|}{ INH prophylaxis } \\
\hline Yes & 27 & 15.7 \\
\hline No & 145 & 84.3 \\
\hline \multicolumn{3}{|c|}{ CTX prophylaxis } \\
\hline Yes & 153 & 89 \\
\hline No & 19 & 11 \\
\hline \multicolumn{3}{|c|}{ ART status } \\
\hline ART & 169 & 98.3 \\
\hline Died & 3 & 1.7 \\
\hline
\end{tabular}

Citation: Ermeko T, Lire F, Lette A, Lamore Y, Wordofa D (2021) Assessment of Associated Factors of Tuberculosis among HIV/AIDS Patients in Misha District, Hadiya Zone, Southern Ethiopia. J HIV AIDS 7(1): dx.doi.org/10.16966/2380-5536.180 
Table 3: Bivariate and multivariable analysis of TB/HIV co-infection among patients in Nigist Eleni referral hospital, Wachemo University, southern Ethiopia, 2018.

\begin{tabular}{|c|c|c|}
\hline Variables & COR $(95 \% \mathrm{Cl})$ & AOR $(95 \% \mathrm{Cl})$ \\
\hline \multicolumn{3}{|c|}{ Marital status } \\
\hline Unmarried & 1 & 1 \\
\hline Married & $0.63(0.323-0.82)^{* *}$ & $2.90(0.58-9.00)$ \\
\hline Divorce & $2.60(0.92-4.61)^{*}$ & $115(0.60-19.34)$ \\
\hline \multicolumn{3}{|c|}{ Residence } \\
\hline Urban & 1 & 1 \\
\hline Rural & $1.76(0.02-10.75)^{*}$ & $2.72(0.38-11.96)$ \\
\hline \multicolumn{3}{|c|}{ Smoking status } \\
\hline Non smoker & 1 & 1 \\
\hline Smokers & $5.12(2.28-19.58)^{* *}$ & $5.98(0.51-11.30)^{*}$ \\
\hline \multicolumn{3}{|c|}{ Functional status } \\
\hline Working & 1 & 1 \\
\hline Ambulatory & $1.37(0.07-15.00)$ & 2.93(0.78-11.09) \\
\hline Bedridden & $3.18(0.09-9.84)^{*}$ & $3.48(0.79-10.84)^{*}$ \\
\hline \multicolumn{3}{|c|}{ WHO stage } \\
\hline Stage 1 & 1 & 1 \\
\hline Stage 2 & $2.00(0.49-17.66)$ & $1.09(0.93-18.54)$ \\
\hline Stage 3 & $1.58(1.39-9.88)^{* *}$ & $2.53(1.09-7.94)^{* *}$ \\
\hline Stage 4 & $3.99(1.15-6.84)^{* *}$ & $3.15(2.045-6.74)^{* *}$ \\
\hline \multicolumn{3}{|c|}{ CD4 count (cell/mm ${ }^{3}$ ) } \\
\hline$<200$ & 1 & 1 \\
\hline $200-350$ & $0.57(0.09-7.09)$ & $0.67(0.11-9.36)$ \\
\hline$>350$ & $0.53(0.01-0.99)^{* *}$ & $0.61(0.21-0.89)^{* *}$ \\
\hline \multicolumn{3}{|c|}{ INH prophylaxis } \\
\hline Yes & 1 & 1 \\
\hline No & $2.79(1.86-9.97)^{* *}$ & $3.62(1.67-9.57)^{* *}$ \\
\hline
\end{tabular}

1 (Reference category); * Odds ratio is significant at $p=0.25 ;{ }^{* *}$ Odds ratio is significant at $p<0.05$.

possible in patients with advanced disease helps the person to have low risk of infection or reactivation of tubercle bacilli. This study revealed that patients with low CD4 number were more likely affected with TB than patients who have higher CD4 count. The odds of occurrence of TB among patients having CD4 count greater than $350 \mathrm{cell} / \mathrm{mm}^{3}$ were $40 \%$ less compared to patients having CD4 number less than 200 cell/ $\mathrm{mm}^{3}$. For example, an observational community-based ART cohort study conducted in South Africa to show short-term and long-term risk of TB related with $\mathrm{CD} 4$ cells recovery during antiretroviral therapy showed that unadjusted TB incidence rates were 16.8, 9.3, 5.5, 4.6, 4.2 and 1.5 cases $/ 100$ person-years, respectively $(\mathrm{P}<0.001)$ [16], during person-time accrued within CD4 cell strata 0-100, 101-200, 201-300, 301-400, 401-500 and more than $500 \mathrm{cell} / \mathrm{mm}^{3}$. Similarly, low level of CD4 count was described as risk factor for increase of tuberculosis in HIV/AIDS patients from Tanzania and Ethiopia [7-10].

Patients who do not receive INH prophylactic were 3.6 times more likely to have TB than those patients who have received INH prophylactic. The role of INH prophylaxis in reduction of occurrence of tuberculosis has been told in many clinical trials and found to be essential [13]. Meta-analysis study carried out on randomized controlled trials of ionized prophylaxis for tuberculosis in HIV infected patients showed that the risk of emerging tuberculosis in the nonprophylactic group was 1.72 times higher than for the prophylactic group [11].
Another important finding of this study was relationship of patient's WHO clinical stage with TB/HIV co-infection. Those patients in III and IV WHO clinical stages were about 2.5 and 3.1 more likely to develop TB compared with those in WHO clinical stages I, respectively. Consistent findings have been reported from Amhara region [17], and Thyolo district, Malawi [18].

\section{Conclusions}

The prevalence of tuberculosis was high to compare with another study conducted in Ethiopia. Tuberculosis was found to be high among ART patients, whose clinical stage III and IV, CD4 cell count $<200$ cell $/ \mathrm{mm}^{3}$ during ART initiation and patients who had not received INH prophylaxis. INH prophylactic preventive measures should be wired to manage cases as early as possible to decrease occurrence of tuberculosis.

\section{Consent to Participate}

The study was done by interviewing the pregnant mothers after an ethical consent was obtained from Wachemo University ethical clearance committee and individual verbal consent was obtained from the study participants. This manuscript has never been submitted and deliberated for publication to any other journal or book.

\section{Availability of Supporting Data}

Data will be available upon request.

\section{Competing Interests}

Have no competing interest and all authors have approved the manuscript for publication.

\section{Funding}

This study had no specific funding.

\section{Acknowledgments}

Authors are thankful to Wachomo University Graduate Study program for supporting this study. We are also very thankful to Nigist Eleni referral hospital for its cooperation to achieve this study.

\section{References}

1. Giri PA, Deshpande JD, Phalke DB (2013) Prevalence of Pulmonary Tuberculosis among HIV Positive Patients Attending Antiretroviral Therapy Clinic. N Am J Med Sci 5: 367-370.

2. Azuonwu O, Putheti R, Amadi F, Obire O (2011) Prevalence of Tuberculosis in HIV infected patients. J Adv Pharm Educ Res 1: 1-11.

3. Maori L (2012) Prevalence of Tuberculosis among HIV/AIDS Patients Attending Zambuk General Hospital. N Y Sci J 5: 33-36.

4. Agbaji O, Ebonyi AO, Meloni ST, Anejo-Okopi JA, Akanbi MO, et al. (2013) Factors Associated with Pulmonary Tuberculosis-HIV CoInfection in Treatment - Naive Adults in Jos, North Central Nigeria. J AIDS Clin Res 4: 222.

5. Yadav DK, Jha N, Pokharel PK, Niraula SR, Bhattacharya SK, et al. (2011) Study on the Prevalence of Pulmonary Tuberculosis among HIV Positive Attending HIV Clinics in Eastern Nepal. SAARC Journal of Tuberculosis, Lung Diseases and HIV/AIDS 8: 1-8.

6. Amuta EU, Mary TI, Akyala IA (2013) A Retrospective Study on the Epidemiological Trend of Human Immunodeficiency Virus (HIV) and Pulmonary Tuberculosis (PTB) Co-Infection in Nasarawa State, Nigeria. J Nat Sci Res 3: 45-51. 
7. Ngowi BJ, Mfinanga SG, Bruun JN, Morkve O (2008) Pulmonary tuberculosis among people living with HIV/AIDS attending care and treatment in rural northern Tanzania. BMC Public Health 8: 341.

8. Wondimeneh Y, Muluye D, Belyhun Y (2012) Prevalence of pulmonary tuberculosis and immunological profile of HIV co-infected patients in Northwest Ethiopia. BMC Res Notes 5: 331.

9. Melkamu H, Seyoum B, Dessie Y (2013) Determinants of Tuberculosis Infection among Adult HIV Positives Attending Clinical Care in Western Ethiopia: A Case-Control Study. AIDS Res Treat 2013: 279876.

10. Taha M, Deribew A, Tessema F, Assegid S, Duchateau L, et al. (2011) Risk factors of active tuberculosis in people living with HIV/AIDS in southwest Ethiopia: A case control study. Ethiop J Health Sci 21: 131 139.

11. Bucher HC, Griffith LE, Guyatt GH, Sudre P, Naef M, et al. (1999) Isoniazid prophylaxis for tuberculosis in HIV infection: a metaanalysis of randomized controlled trials. AIDS 13: 501-507.

12. Zar HJ, Cotton MF, Strauss S, Karpakis J, Hussey G, et al. (2007) Effect of isoniazid prophylaxis on mortality and incidence of tuberculosis in children with HIV: randomised controlled trial. BMJ 334: 136.
13. Kamyar A (2003) The effect of one year INH prophylaxis in reduction of clinical TB in HIV-infected injecting drug user males. Tanaffos 2: 57-61.

14. Denegetu AW, Dolamo BL (2014) HIV Screening among TB Patients and Co-Trimoxazole Preventive Therapy for TB/HIV Patients in Addis Ababa: Facility Based Descriptive Study. PLOS One 9: e86614.

15. do Prado TN, Miranda AE, de Souza FM, Dias Edos S, Sousa LK, et al. (2014) Factors associated with tuberculosis by HIV status in the Brazilian national surveillance system: a cross sectional study. BMC Infect Dis 14: 415.

16. Lawn SD, Myer L, Edwards D, Bekker LG, Wood R (2009) Short-term and long-term risk of tuberculosis associated with CD4 cell recovery during antiretroviral therapy in South Africa. AIDS 23: 1717-1725.

17. Mitku AA, Dessie ZG, Muluneh EK, Workie DL (2016) Prevalence and associated factors of TB/HIV co-infection among HIV Infected patients in Amhara region, Ethiopia. Afr Health Sci 16: 588-595.

18. Teck R, Ascurra O, Gomani P, Manzi M, Pasulani O, et al. (2005) WHO clinical staging of HIV infection and disease, tuberculosis and eligibility for antiretroviral treatment: relationship to CD4 lymphocyte counts. Int J Tuberc Lung Dis 9: 258-262. 